\title{
National Alliance of Breast Cancer Organizations
}

National Cancer Institute

\section{Source}

National Cancer Institute. National Alliance of Breast Cancer Organizations. NCI

Thesaurus. Code C39464.

The National Alliance of Breast Cancer Org anizations is a New York-based non-profit education and information resource on breast cancer in the US. 